Pasado y Memoria

ISSN: 2386-4745

Núm. 24, 2022, pp. 356-373

https://doi.org/10.14198/PASADO2022.24.15

Documenta inedita

\title{
Dos escritos inéditos de Jovellanos sobre la Constitución histórica
}

\section{Two unpublished Jovellanos' writings about the Historical Constitution}

\author{
Ignacio Fernández Sarasola \\ Universidad de Oviedo, España \\ sarasola@uniovi.es \\ https://orcid.org/0000-0002-2638-4108
}

Recibido: 05/10/2021

Aceptado: 05/11/2021

Cómo citar este texto: FERNÁNDEZ SARASOLA, Ignacio (2022). Dos escritos inéditos de Jovellanos sobre la Constitución histórica. Pasado y Memoria. Revista de Historia Contemporánea, (24), pp. 356-373, https://doi.org/10.14198/ PASADO2022.24.15

\section{Resumen}

La teoría del Estado de Jovellanos se adscribía al iusracionalismo, principalmente ligado a autores como Christiaan Wolff y Samuel Puffendorf, Jean-Jacques Burlamaqui, Gottlieb Heinnecio, Jean Domat y Hugo Grocio. A su parecer, además de emplear las obras de estos autores en los estudios jurídicos cursados en España, debía adoptarse su metodología, sustituyendo así el enfoque escolástico tradicional aplicado en España. Jovellanos se adscribía a los planes de reforma de los estudios jurídicos diseñados por Gregorio Mayáns y Pablo de Olavide. Él mismo había estudiado leyes y cánones, pero consideraba que su formación académica no había sido adecuada. De hecho, durante el siglo XVIII, la mayoría de los juristas españoles, tras culminar sus estudios universitarios, debían recibir una formación específica para poder conocer las normas legales españolas que no habían aprendido en la Universidad, donde el Derecho Romano seguía siendo la única fuente legal explicada.

Si bien la teoría del Estado de Jovellanos seguía esa línea de pensamiento iusracionalista, su idea de Constitución seguía planteamientos historicistas. Rechazaba la idea de una Constitución nacida del ejercicio del poder constituyente, obviando 
así las doctrinas de Emmanuel Joseph Sieyès. Muy al contrario, consideraba que las constituciones nacen a partir de un proceso histórico. Aun así, en sus primeros escritos Jovellanos no identificaba «Constitución» con Leyes Fundamentales, sino con la estructura socio-política de un país.

Ambos textos inéditos que se presentan muestran las teorías jovellanistas sobre 'Estado' y 'Constitución'. El primero de ellos es el borrador de dos cartas dirigidas a un destinatario desconocido. No fue incluido en las Obras Completas de Jovellanos. El segundo parece ser el desarrollo de un borrador destinado a una nueva edición del Fuero Juzgo encargado por la Real Academia Española.

Palabras clave: Jovellanos; Constitución histórica; Iusracionalismo; Fuero Juzgo; Ilustración.

\begin{abstract}
Jovellanos' State Theory held on iusrationalism, mostly linked to thinkers such as Christiaan Wolff, Samuel Puffendorf, Jean-Jacques Burlamaqui, Gottlieb Heinnecio, Jean Domat and Hugo Grocio. According to him, those authors' works should substitute the old texts used in Spanish Legal Studies and their methodology should replace the traditional scholastic method used in Spain. Jovellanos fuly agreed with the plans to reform the Spanish legal studies designed by Gregorio Mayáns and Pablo de Olavide. He himself had studied Law and Canons, but he found that his academic education had not been accurate. In fact, in the $18^{\text {th }}$ century, after completing their university studies, most jurists had to complete their training with the study of the Spanish Legal System, which they had not learnt at the University, where Roman Law continued to be the only legal system taught.

But while Jovellanos' State theory followed the iusrationalism line of thinking, his Constitutional theory was inspired by historicism. He rejected the idea of a Constitution deriving from constitutional power, thus ignoring Emmanuel Joseph Sieyès doctrines. On the contrary, he thought that constitutions derived from a historical process. Nevertheless, Jovellanos first writings did not identify Constitution with Fundamental Laws, but with the social and political structure of a country.

Both unpublished texts now presented illustrate Jovellanos' theories about 'State' and 'Constitution'. The first one is the draft of a couple of letters addressed to an unknown person. It was not included in Jovellanos' complete works. The second document seems to be a draft intended for a new edition of the «Fuero Juzgo» as requested by the Royal Academy of the Spanish Language.
\end{abstract}

Keywords: Jovellanos; Historical Constitution; Iusrationalism; Fuero Juzgo; Enlightenment.

\title{
Dos inéditos de temática constitucional
}

En un escritor tan prolífico como fue Gaspar Melchor de Jovellanos resulta casi anecdótico hallar un documento suyo perdido en las docenas de archivos entre los que sus papeles lamentablemente se encuentran desperdigados. A pesar de ello, cada texto rescatado del olvido arroja algo más de luz, tanto sobre su 
ideario como sobre su infatigable actividad. Los dos documentos inéditos que ahora recuperamos aportan en concreto datos de interés en torno a una de las facetas más polémicas del polígrafo asturiano: su pensamiento constitucional.

El primero de ellos se halla localizado en la Biblioteca Pública de Gijón. Se trata de dos borradores de cartas de Jovellanos (el segundo incompleto), copiados en 1885 por Julio Somoza. Según apunta Somoza en la transcripción, las misivas originales eran propiedad de Alejandro Alvargonzález, y a día de hoy se han perdido. Las epístolas, a las que Somoza añadió un título de cosecha propia bastante ajustado al contenido del texto («Reflexiones sobre la Constitución, las leyes, usos y costumbres de Castilla») no fueron tampoco incluidas en su día en los volúmenes que a las Obras completas del ilustrado gijonés dedicó José Miguel Caso González. Respecto a la datación del original, la Somoza apunta a que debió haberse redactado en la década de los años ochenta del siglo XVIII, aunque por su contenido también podría pertenecer a la década siguiente, incluso con más probabilidad. Y es que las misivas contienen unas reflexiones muy similares a las que Jovellanos vertió en sendas misivas destinadas a Antonio Fernández de Prado (17 de diciembre de 1795) y Juan Francisco Madeu (borrador datado en 1800).

El segundo texto - un autógrafo de Jovellanos sin fecha- es de procedencia incierta. Una fotocopia de él se conserva en el Instituto Feijoo de Estudios del Siglo XVIII, de donde fue transcrito, aunque sin referencia a su localización. Como veremos, todo parece apuntar a que el texto pudo haberse obtenido del Archivo de la Real Academia Española, aunque las pesquisas para localizarlo han resultado infructuosas. A este segundo texto me referiré en lo sucesivo como «Esquema sobre la Constitución y leyes de España», título que yo mismo le he atribuido para poder referirme a él en este trabajo.

El contexto y datación de este segundo documento tampoco es claro. A mi modo de ver, podría tratarse de un esquema elaborado por Jovellanos como complemento o en desarrollo de su «Plan de Disertación sobre las Leyes Visigodas», elaborado en 1785 por encargo de la Real Academia de la Lengua para una edición crítica del Fuero Juzgo que finalmente elaboraría el penalista ilustrado Manuel de Lardizábal y Uribe (García Marín, 2016). De hecho, en el mencionado plan, Jovellanos ya había incluido un esquema muy básico, en el que figuraba un apartado dedicado a la "Constitución», y que podría ser precisamente el que desarrollase el inédito aquí publicado.

Ciertamente, los documentos no aportan grandes novedades acerca del pensamiento político-constitucional y jurídico de Jovellanos, pero refuerzan algunas de las ideas que sobre él he tenido ocasión de exponer en anteriores estudios. Ideas que apuntalan su teoría del Estado y de la Constitución. 


\section{La formación del jurista}

La Teoría del Estado jovellanista resulta compleja, porque en ella confluyen líneas de pensamiento e influencias muy diversas. Quizás por ello existe un aspecto que la historiografía no siempre ha percibido con claridad, a saber, que la teoría del Estado de Jovellanos es claramente iusracionalista, por más que su teoría de la Constitución sea historicista. Y ambos aspectos no resultan necesariamente contradictorios: si el origen de la sociedad y el Estado podía fundamentarse en un orden natural -que en Jovellanos, a diferencia de Hobbes y Spinoza, se caracteriza por la sociabilidad humana-, una vez formada la comunidad y el poder público éste podía decidir sus formas de gobierno, momento a partir del cual deviene necesario un respeto a las instituciones antiguas para las generaciones sucesivas.

Es en el primero de los documentos ahora publicados - «Reflexiones sobre la Constitución, las leyes, usos y costumbres de Castilla»-donde se contienen más apuntes sobre la teoría del Estado iusracionalista de Jovellanos. El punto de partida reside en la definición de política que realizaba en el documento, entendida como disciplina que se ocupa de regular las relaciones de los individuos con la sociedad. Esta parca definición se concretaría a través de la Introducción a un discurso sobre la economía civil y la instrucción pública (1796-1797), donde el gijonés añadiría que la política se ocupaba de dos relaciones: la del Gobierno con los gobernados y la de los Gobiernos entre sí. El Derecho Natural y el Derecho público Universal regularían la primera de dichas relaciones, en tanto que el Derecho Patrio atendería a la segunda (Jovellanos, 2010: 659-680, 797).

Qué fuentes y qué método debían emplearse para estudiar esas diversas ramas jurídicas fue una cuestión que a Jovellanos, como jurista, le interesó especialmente. Su formación en Leyes y Cánones en la Universidad de Ávila le había llevado a repudiar el método escolástico que él mismo había sufrido, y que por aquel entonces se empleaba en los estudios de Derecho: «Entré en la jurisprudencia sin más preparación que una lógica bárbara y una metafísica estéril y confusa» (Jovellanos, 1963: 288). Lamentación que reitera en las «Reflexiones» aquí transcritas: «¡Cuánto tiempo perdido en estudios estériles!».

Al margen del método, las facultades de leyes españolas mantenían unos estudios basados en el Derecho Romano, lo que les procuraba una formación puramente teórica con la que llegaban a los despachos de abogados, donde descendían a la práctica de aplicar un Derecho patrio con el que no estaban familiarizados (Peset, 1971). Esta carencia de los egresados a menudo se compensaba a través de las Academias de práctica jurídica que se establecieron en el siglo XVIII precisamente para paliar la deficiencia de los estudios universitarios 
(Alonso Romero et al., 2013: 35). En 1713 y 1741 Felipe V había tratado que las Universidades españolas enseñasen el Derecho nacional, pero con escasa fortuna, de modo que la situación no empezó a enmendarse hasta el reinado de Carlos III. En su proyecto de plan de estudios para la Universidad de Valencia de 1786, Mayáns ya propondría crear una cátedra de Derecho español, que debía guiarse por las Instituciones del Derecho Civil de Castilla (1771) de los doctores Ignacio Jordán de Asso y Miguel de Manuel y Rodríguez que, por otra parte, causarían en Jovellanos una honda impresión (Jovellanos, 1996: 80). La obra de Asso y Manuel -inspirada principalmente en Las Partidas, la Recopilación, el Fuero Real y el Fuero Juzgo- tendría un enorme impacto para la incorporación del Derecho español a las Universidades.

Al margen del Derecho patrio, Mayáns también apuntó a otra reforma de gran calado en las facultades de leyes: en su proyecto de 1767 -cimentado tras la expulsión de los jesuitas- apuntaría la necesidad de introducir en los estudios jurídicos el moderno Derecho Natural y de Gentes (Peset, 1995: 93), querencia que compartiría Pablo de Olavide (Peset et allii, 1975: 293). De este modo, en 1774 verían la luz al fin las primeras cátedras de Derecho Natural y de Gentes, aunque resultaron escasas (Álvarez de Morales, 1993: 141, 153). Aprovechando esta circunstancia, el valenciano Joaquín Marín y Mendoza abordaría la redacción de un pobre manual para la disciplina, en la que ésta se hallaba debidamente depurada de autores cuestionables en España, como Jean-Jacques Rousseau, a quien describía como «opuesto a todo el buen orden y la quietud pública» (Marín y Mendoza, 1950: 54).

El propio Mayáns había propuesto como obra más conveniente -siquiera de forma temporal- las obras de Heineccio, autor que alcanzó un gran éxito debido a su eclecticismo (Álvarez de Morales, 1993: 148). Por su parte, Olavide trató de incorporar las nuevas corrientes de forma más abierta (Peset et allii, 1975: 222): nada más perjudicial, decía el peruano, que el espíritu escolástico «de horror y de tinieblas, que nació en los siglos de la ignorancia» (Olavide, 1989: 85). En jurisprudencia era preciso superarlo mediante el estudio del Derecho Natural y de Gentes, imprescindible para comprender «las obligaciones del hombre en el estado natural y social (...) formar idea cabal del legítimo interés del Estado y de los ciudadanos», a cuyos efectos recomendaba a Grocio y Pufendorf (Olavide, 1989: 131).

En las facultades de cánones, por su parte, las enseñanzas estaban inicialmente marcadas por el estudio de las Decretales, si bien el regalismo propició un cierto cambio de enfoque, convirtiendo a Zeger Bernhard Van Espen en el autor de referencia y recuperando la disciplina más antigua inserta en el Corpus Iuris Canonici, al ser ésta más armónica con la idea de un poder monárquico 
autónomo del papado. En este sentido, puede decirse que las facultades de leyes y de cánones discurrían por caminos opuestos: en tanto las primeras asumían las tendencias más modernas (el Derecho Natural y de Gentes), las segundas se orientaban hacia fuentes más pretéritas (Pesset et allii, 1975: 302). Aunque, en realidad, la divergencia resulta tan solo aparente: tanto una como otra dirección permitían consolidar el poder regio, porque si así sucedía con el recurso a las antiguas fuentes canónicas, otro tanto permitían los autores del Derecho Natural y de Gentes empleados, como Wolff, Puffendorf o Heineccio, muchos de los cuales se hallaban ligados al cameralismo germano y a la idea de despotismo ilustrado.

Jovellanos representa toda esta nueva filosofía que debía guiar la formación del jurista ilustrado en las tres ramas jurídicas ya referidas: el Derecho Natural, el Derecho Público Universal y el Derecho Patrio. El primero tendría como fundamento conocer «los derechos imprescriptibles del hombre» y sus obligaciones, nacidos ambos de la razón luego perfeccionada por el elemento religioso (Jovellanos, 2010a: 669-670). Su estudio debía realizarse a partir de los escritos de Francis Hutcheson, padre de la ilustración escocesa y autor del System of Moral Philosophy (1755). También tenían cabida De lege naturali positiones in usum auditorii vindobonensis (1762), del austríaco Karl Anton von Martini, que se convertiría en una referencia también en Portugal (Truyol y Serra, 1982: 357). Pero, sobre todo, Jovellanos admiraba la obra del germano Christian Wolff, a quien constantemente citaba como la referencia inexcusable para conocer el ius Gentium y el ius naturae (Jovellanos, 2010b: 847) explicado, además, con el método que el gijonés consideraba más convincente: more geométrico.

Hasta qué punto Jovellanos siguió este iusracionalismo es algo que no siempre se ha sabido asumir. Se le ha ligado erróneamente a la neoescolástica española, cuando en realidad sus fuentes principales fueron pensadores iusracionalistas como Grocio, Burlamaqui, Heineccio, Pufendorf o Wolff, sin perjuicio de que estos, a su vez, hubiesen recibido un notable influjo por parte de autores del barroco español, como Francisco Suárez, Domingo de Soto o Francisco de Vitoria (Fernández Sarasola, 2011).

El propio Wolff serviría como autor para el estudio del Derecho Público Universal, en el que igualmente debían seguirse las enseñanzas de Hugo Grocio y de Samuel Puffendorf. Este Derecho Público, o ius Gentium, regulaba las relaciones de los Estados entre sí y, junto con el Derecho Público interior o Derecho nacional, formaba la esencia del arte del gobierno (Jovellanos, 2008: 892). En su diario, Jovellanos había dejado clara su intención de promover el estudio de ese derecho público universal en las cátedras de filosofía moral 
(Jovellanos, 1999: 92). Y en su proyecto de reglamento para el Colegio de la Inmaculada Concepción de Salamanca, el gijonés incluía la enseñanza del Derecho Público Universal tanto para el estudio del Derecho Canónico como para el de la ética (Jovellanos, 2010a: 669-673).

El Derecho Patrio o Nacional ocupaba el último tramo de la formación del jurista, y comprendía tanto el Derecho Público español (que regulaba las relaciones entre el Gobierno y los gobernados) como el Derecho Privado (relaciones intersubjetivas) (Jovellanos, 2010b: 1371). Siguiendo las propuestas ilustradas, Jovellanos apostaba por relegar a un segundo plano el estudio del Derecho Romano, antaño principal fuente del jurisconsulto (Jovellanos, 2010b: 855-857). La formación del Derecho patrio comprendía, a su vez, dos bloques bien diferenciados. Por una parte, era preciso el estudio de las propias fuentes normativas que configuraban tanto la «antigua Constitución» como las leyes nacionales y municipales. Sus referencias se ceñían, sin embargo, sólo al Derecho castellano, acudiendo sobre todo al Fuero Juzgo, Las Partidas y la Nueva Recopilación, norma esta última esencial al contener, según Jovellanos las normas pactadas por el soberano con las Cortes (Jovellanos, 2010a: 678).

Aparte de las fuentes normativas, el jurista debía conocer lo que al respecto habían analizado sus principales tratadistas, recomendando en este punto, entre otras, la consulta de las Observaciones sobre las Leyes de España (por otros citada como Sobre las leyes y los fueros de España) de Francisco Espinosa, obra hoy poco conocida y menos accesible (Sánchez, 1927) (Maldonado y Fernández del Torco, 1942-1943). También le placía la carta del padre Andrés Burriel al licenciado Juan de Amaya Sobre nuestros antiguos códigos, publicada a decir de Jovellanos en el Semanario Económico, si bien parece que se habría tratado del Semanario erudito (Jovellanos, 2010a: 677). Lo escasamente accesibles de estas obras demuestra hasta qué punto el estudio del derecho patrio se hallaba todavía en ciernes. Había, sin embargo, una obra que había venido a solventar en buena medida esta circunstancia y que Jovellanos no se olvidaba de mencionar: las ya referidas Instituciones de Castilla de Asso y Manuel. En todo ese entramado, Jovellanos cifraba la formación del jurista que, yendo de lo general -el Derecho Natural y el Derecho Público universal- llegase a conocer igualmente las particularidades normativas de España.

\section{La Constitución histórica y la recuperación de las Leyes Fundamentales}

Si las «Reflexiones» incluían pinceladas sobre el Derecho Natural, el Derecho Público Universal y el Derecho Nacional, el «Esquema» que aquí también se transcribe se refería exclusivamente a este último. En él trazaba los elementos de la «Constitución española» que, en realidad, no identificaba con un 
producto normativo resultante de un proceso constituyente. Jovellanos jamás aceptó las teorías de Sieyès, ni los planteamientos que habían conducido al nacimiento del constitucionalismo revolucionario de Francia.

El concepto de Constitución sostenido por Jovellanos evoluciona a lo largo del tiempo, pudiendo apreciarse tres etapas: la de aproximación (17701790), la de fijación del concepto (1791-1802) y la de consolidación del mismo (1808-1811) (Fernández Sarasola, 2011: 32-49). En la primera identificaba la Constitución con el entramado social, político y económico de la sociedad, si bien desde 1780 empezaría a reservar el término de Constitución para referirse sólo a la estructura política de la sociedad civil, por lo que utilizó frecuentemente la expresión «Constitución política». En la segunda fase, Jovellanos altera su idea original, transitando a un concepto de Constitución histórica que se desprende de elementos fácticos y se identifica con las Leyes Fundamentales que a materializan un pacto entre el Rey y las Cortes. Finalmente, en la tercera etapa Jovellanos define con mayor detalle esta última idea constitucional, concretando el contenido que permitiría identificar qué leyes históricas tenían la condición de «fundamentales»: las que regulaban las prerrogativas del Rey, los derechos de la Nación, los derechos de los individuos que componían la Nación, la forma de gobierno, y el Derecho Público interior (Jovellanos, 2006: 650-653). En esta última fase, como vocal de la Junta Central, llegó a promover la formación de una Junta de Legislación asesora que precisamente asumiese la tarea de recopilar las Leyes Fundamentales que cumpliese con las referidas regulaciones.

Todo apunta a que el «Esquema» se corresponde con la primera etapa del pensamiento constitucional de Jovellanos, ya que en él la Constitución se identifica claramente con elementos fácticos, y no exclusivamente con productos normativos históricos. El «Esquema» comenzaba fijando el origen de la Constitución española que, de lo que se deduce del escrito, comprendería cuatro fases: la Constitución visigoda, la surgida con el reinado de Asturias, la que emergería a raíz de la unión de las dos Castillas y finalmente la resultante de la reunión de las coronas de Castilla y Aragón bajo la égida de los Reyes Católicos. En el segundo apartado, Jovellanos desbrozaba los elementos de esa Constitución que no eran otros que los distintos elementos sociopolíticos del reino: el Rey -al que, como siempre haría, aplica el título de «soberano»-, la nobleza, el clero y el pueblo. Resulta evidente que Jovellanos está, por tanto, definiendo a esas clases como elementos estructurales de la Constitución, pero, por lo mismo, implícitamente podía dar a entender la oportunidad de unas Cortes, ya que sólo en ellas podría darse cabida a los tres estamentos que la comprendían. No en balde, incluso en un panegírico al rey que más había 
admirado -el Elogio a Carlos III (1789) - el asturiano había tenido la osadía de mencionar a las Cortes en términos laudatorios, a pesar de que habían estado ausentes durante aquel reinado.

Finalmente, en el último apartado del «Esquema», titulado «Legislación» Jovellanos incluía lo que en su siguiente fase de pensamiento constitucional identificaría con la "Constitución histórica», es decir, las Leyes Fundamentales, mencionando la legislación visigoda y fueros locales, el Fuero Real, Las Partidas y La Recopilación. Ahora bien, en el momento en que redacta el «Esquema» todo apunta a que esas leyes no se identifican con la Constitución misma, sino que representan un elemento más de ella.

Claramente el texto se halla ligado al Discurso de recepción a la Real Academia de la Historia, expuesto por el gijonés en 1780, y en el que sostiene unas ideas prácticamente idénticas a las que se plantean en el «Esquema». La primera Constitución sería la visigoda, caracterizada por la reunión a iniciativa del Rey de Concilios o Cortes y que Jovellanos describe con palabras de admiración, abriendo el camino al mito de la «Constitución gótica» que, asentada en un historicismo deformador, luego utilizarían los liberales doceañistas. Esta Constitución habría sufrido una «revolución», primero con el ascenso al poder temporal del clero, a partir de los Decretos de Recaredo (siglo VI), y después con la invasión árabe. De aquí se extrae que la legislación nacional no se identifica con la Constitución, pero puede conllevar su alteración, del mismo modo que también los hechos sociopolíticos también podían conducir a ese mismo resultado.

La Reconquista (siglo VIII) iniciaba una nueva voluntad restauradora de la Constitución Visigoda, pero habría resultado imposible ante la situación bélica. Antes bien, el «ser» condicionaba el «deber ser», surgiendo una Constitución muy diferente de la antigua, caracterizada por el incremento del poder nobiliario (auténtico sostén de la guerra) y la concesión de fueros particulares a los municipios. En definitiva, se producía una situación de privilegios particulares, de clase o de burgos, que generaban una dispersión del poder que se traducía en una Constitución con patentes defectos: un Monarca débil y un pueblo que no era libre, ahogado por la nobleza a quien había de mantener. La legislación resultante aparecía, como la propia Constitución, vacilante y heterogénea.

Una nueva Constitución surgiría a partir, nuevamente, de un cambio en la situación histórica y, en parte, de la legislación nacional: la expulsión de los musulmanes y la unión de Castilla supondría la decadencia de las clases altas y la concentración del poder regio, a la par que el pueblo recuperaría su libertad mediante la convocatoria frecuente de Cortes. A ello habría contribuido 
también, como se ha dicho, un cambio legislativo: la armonización de la legislación a través del código de Las Partidas (1252-1284).

El concepto de Constitución así utilizado por Jovellanos en poco difería al de William Robertson. Este autor, al analizar la historia española durante el reinado de Carlos V, había identificado la Constitución «política» con la forma de gobierno y reconocía la existencia de distintas Constituciones que se habían sucedido durante la historia de la nación española: primero la Constitución goda, que se vería sustituida a raíz de la ocupación musulmana y posterior Reconquista, que darían lugar a un Monarca muy limitado y a una Constitución feudal, a excepción de Aragón, que, con un gobierno monárquico, se regiría por máximas republicanas. Finalmente, con los Reyes Católicos surgiría una nueva Constitución caracterizada por la unidad nacional y el incremento de poder regio (Robertson, 1857: 66-68). Ideas, pues, muy semejantes a las del ilustrado español.

En todo caso, es posible percibir que la dinámica constitucional que fija Jovellanos en su Discurso de recepción a la Real Academia de la Historia entraña una traslación del poder gubernativo y es ésta, precisamente, la que determina cada «nueva Constitución» que sustituye a la anterior. Así, en la Constitución gótica lo determinante era la presencia de una institución representativa, es decir, la participación política de la comunidad, aunque esta se hallase estratificada. De ahí se pasaría entre los liberales a forjar el mito de la «Constitución gótica», viendo en ella, de forma interesada y desde luego muy distante a la realidad histórica, una «democracia» (Álvarez Alonso, 2000). Jovellanos contribuyó, de forma inconsciente, a forjar ese mito, aunque él siempre atendió más al ejemplo de la "Constitución castellana» (de sesgo más monárquico) que a la "Constitución aragonesa» (de tendencia más "popular»), preferida sin embargo por los liberales. En la segunda etapa constitucional descrita por Jovellanos sería uno de los elementos de esa comunidad estamental, el clero, el que lograría un incremento de su poder, sólo para verse reemplazado en ese papel por la nobleza a partir de la Reconquista, momento en el que la fuerza de las armas permitió a los nobles asumir mayor potestas. De la comunidad al clero, del clero a la nobleza, y el último tramo quedaría completado cuando los Monarcas lograsen concentrar ese poder, no sólo por encima de clero y nobles, sino incluso de la institución representativa (Cortes) dando lugar a una Monarquía cada vez más absoluta que se perpetuaría hasta el siglo XVIII.

\section{Conclusiones}

Los nuevos documentos jovellanistas hallados no hacen sino corroborar algunas de las conclusiones que ya habíamos planteado en estudios anteriores 
sobre el pensamiento político-constitucional del ilustrado asturiano. Por una parte, su adscripción a una teoría del Estado de sesgo iusracionalista, en la que muestra su preferencia por un grupo doctrinal que la historiografía posterior ha definido en ocasiones como «iusracionalistas menores» (Burlamaqui, Domat, Heinnecio...), a los que se añaden otras figuras muy notables, como Christian Wolff, Samuel Puffendorf y Hugo Grocio. En los mencionados textos se corrobora que Jovellanos era partidario de sustituir en las enseñanzas de jurisprudencia el método escolástico por la nueva metodología derivada del ius Gentium y del ius naturale, y que, en ausencia de manuales adaptados a tal cambio, proponía la lectura de aquellos autores mencionados.

Por otra parte, ambos documentos, pero sobre todo el segundo (el «Esquema sobre la Constitución y leyes de España»), contienen también reflexiones que ratifican la teoría de la Constitución jovellanista. Se evidencia que ésta fue evolutiva, y que por tanto el concepto de Constitución que sustentó en hasta la década de los años 90 del siglo XVIII no era la misma que sostuvo a partir de esa fecha. El «Esquema» en particular parece pertenecer a la primera de las mencionadas etapas, en las que Jovellanos identificaba la Constitución con el entramado político-social y no con una norma jurídica específica fruto de un poder constituyente (idea «racional-normativa» de Constitución, que nunca sostuvo) ni tampoco con un corpus legal integrado por las Leyes Fundamentales (idea que fue precisamente la que defendió desde 1790 hasta el fin de sus días).

\section{ANEXOS}

Reflexiones sobre la Constitución, las leyes, usos y costumbres de Castilla [1780-1790]

Carta primera sobre la Constitución, las leyes, usos y costumbres de Castilla

Tiene usted (vuesa merced) mil razones, amigo mío; el estudio del hombre debe ser el hombre mismo. Ninguno tan necesario, tan útil, tan deleitoso. Los demás estudios pueden ilustrar el espíritu; este solo enriquecerle. Los demás harán al hombre sabio, pero este le hará justo.

No crea usted, por eso, que cuando haya reducido todo estudio y a sus meditaciones a este solo objeto, ha dejado sobre sus hombros una carga ligera. El estudio del hombre es un objeto tan vasto, tan poco conocido, tan importante, que ningún otro pide más aplicación ni mayores talentos.

Es un objeto muy vasto porque, para conocer al hombre, es menester estudiarle bajo de todas las relaciones que tiene respecto de su Criador, respecto de sí y de sus semejantes. No basta conocer la esencia, es menester conocer sus 
obligaciones. Porque ¿quién podrá conocerlas si no le considera con relación a los objetos a que se dirigen?

Es objeto poco conocido, porque ¿quién hasta ahora ha definido exactamente la esencia del hombre?, ¿quién ha puesto en claro el número ni la existencia de sus obligaciones?

Es principalmente un objeto importante porque ha nacido el hombre al mundo solo para existir en él un cierto periodo de tiempo. Ha nacido para llenar el fin de su creación. No debiendo su existencia a la casualidad, es preciso que la suprema inteligencia que le puso en el mundo exija de él el cumplimiento de aquellos fines para que le ha criado. Para cumplirlos, es absolutamente necesario conocerlos.

Por eso, el estudio solo del hombre envuelve en sí una especie de enciclopedia universal, una suma inmensa de conocimientos que abraza, por decirlo así, todas las ciencias.

Considere usted al hombre con relación a su Criador y hallará usted el objeto de la más sublime Teología. Considérele con respecto a sus semejantes, y hallará usted el de la Ética muy provechosa. Considérele, en fin, con respecto a la sociedad en que vive, y este será el objeto de la mejor Política.

De aquí es que, siendo tan limitado el espíritu del hombre y no pudiendo abrazar de una vez muchas y muy extendidas ideas, conviene que se entregue con preferencia al estudio de una parte de las obligaciones del hombre mismo. Conviene que algunos cultiven particularmente las obligaciones del hombre como criatura de Dios: algunos, los que tiene como habitador de un mundo que está poblado de criaturas semejantes a sí, a quienes tiene obligación de servir y socorrer y de quienes tiene derecho de esperar los mismos auxilios; y que otros le consideren como miembro de una sociedad compuesta de cierto número de hombres que, para cumplir mejor la obligación natural de socorrerse recíprocamente, han añadido a ella una suma de obligaciones particulares, fundadas todas sobre la razón del interés general y recíproco.

Ahora bien, amigo mío, si usted tiene bastantes fuerzas para estudiar al hombre bajo de estas diferentes relaciones, si la perspectiva de un país tan dilatado y lleno de tropiezos no le asusta, cíñase de valor y constancia y acometa en buen hora tan difícil pero tan ilustre carrera. En cuanto a mí, que he pasado ya la mejor y aun la mayor parte de mi vida, que vivo en una gran penuria de tiempo y reposo y que por mi empleo y profesión veo a todas horas al hombre lidiando con los individuos de la sociedad en que viven, preferiré siempre la última parte de este estudio, esto es, aquella en que el hombre es considerado como miembro de una cierta y determinada sociedad. 
Pero aun este objeto será demasiado vago y extendido si yo le considerase en abstracto. Por eso me ha parecido reducir mi estudio al hombre como miembro de esta misma sociedad en que vivo y en cuyos paredones formo yo mismo una partida.

Vea usted aquí el objeto de mis actuales estudios, y iojalá que lo hubiese sido desde que he elegido la carrera en que vivo! ¡Cuánto tiempo perdido en estudios estériles! ¡Cuánto afán, cuántas tareas vanamente empleadas en libros inútiles!

Pero este fue un mal necesario. Usted sabe que lo único que elige un joven dedicado a las letras es el objeto de su estudio. Lo demás lo hacen los maestros. Estos eligen los libros, se los ponen en la mano y se constituyen fiadores de la importancia de su doctrina. Pero ¡qué maestros suele ofrecer la suerte! ¡Qué libros suelen merecer la preferencia en la estimación de estos maestros!

¡Dichoso usted, que ha nacido en mejor época, y cuyos primeros estudios son mejor dirigidos! ¡Dichoso usted, a quien no son desconocidos ni la exacta Lógica de Condillac ni la sublime Metafísica de Lock!, ique ha ilustrado su entendimiento con el estudio de la Geometría, le ha enriquecido con la buena Física y ahora le va adornando con las profundas lecciones de la Ética!

Pues ármese usted, amigo mío, de nueva constancia. Aún tiene abierto ante sus ojos un campo vastísimo por donde debe dirigir la larga carrera. Está usted ya a las puertas del estudio del Derecho y, aunque los conocimientos adquiridos le facilitarán la entrada, ¡cuánto afán, cuánto sudor no habrá de sufrir antes de penetrar a su santuario!

En el estudio del Derecho natural, de gentes y público que va a emprender, ¡cuántas dificultades no le amenazan desde el primer pago! ¿Dónde, me dice usted, encontraré libros para hacer este estudio? No lo sé.

Veo notados con negra censura los nombres de los más ilustres maestros, y no me atrevo a proponerlos ni a desecharlos: Grocio, Puffendorf, Burlamaqui, Wolff, Wattel ... sería conveniente que una pluma sabia y atinada entresacase de las obras de estos doctos varones los principios más puros del Derecho primitivo y los propusiese a nuestra nación, purgados de las heces que obligaron a proscribirlos. Pero ¿a dónde se acudirá entretanto? No lo sé.

Acaso desde este estudio piensa usted pasar al de las Instituciones de Justiniano y de su docto comentador Arnoldo Vinio. ¿Qué podré yo decir a usted sobre este método? Una nación entera le aprueba, la costumbre de seis siglos le hace respetable, los más ilustres magistrados le han autorizado, y ¿me atreveré yo a decir que es pernicioso?

Mas ¿por qué he de callar? ¿Por ventura el número, el tiempo ni la autoridad de las opiniones podrán prescribir contra la verdad? 
La única razón que puede alegarse por el estudio del Derecho Romano es la de ser origen de la mayor parte de nuestras leyes. Séalo en buena hora. Acuda el jurisconsulto a perfeccionar sus conocimientos con el estudio de las fuentes. Pero ¿se infiere de aquí que este Derecho debe formar una parte del estudio elemental de los jóvenes legistas?

Y ¿qué digo, una parte? ¿Se ha hecho hasta ahora en nuestras escuelas otro estudio? Salamanca, Valladolid, Alcalá, ¿han oído jamás explicar en sus aulas alguna ley de los Códigos de Castilla?

Se ha introducido en estos últimos tiempos la explicación de las leyes de Toro en nuestras universidades, pero este [es] un remedio muy parcial y, la forma de su aplicación, le puede hacer pernicioso.

El estudio mismo del Derecho Romano suscitó tal muchedumbre de dudas y opiniones entre nuestros pragmáticos que fue preciso fijarlas. La nación junta en la cortes de Toro, en 1+ [...] lo acordó así. Juntándose los mayores jurisconsultos del reino, tuvieron muchos y muy reñidos debates $y$, al fin, formaron ochenta y tantas leyes, para fijar otros tantos puentos en que estaban divididos los ánimos. Estas leyes son un breve suplemento añadido a nuestro Derecho. ¡Qué buena obra para estudiar las leyes de España!

Comentó primero estas leyes el célebre asturiano Miguel de Cifuentes, mi compatriota; siguiéronle Palacios Rubio, Télez y Antonio Gómez. El peor de todos estos comentadores es el último. Sin embargo, se explica por él en las escuelas.

¿Con qué desterramos el estudio del Derecho Romano de las escuelas de España? Después de haber introducido en ellas los buenos y bien ordenados estudios, es absolutamente necesario.

Usted quiere saber cuáles son estos estudios, y quiere muy bien. Voy a decir mi dictamen.

Supongo que nadie deberá entrar al estudio del Derecho Español sin haber estudiado antes las Humanidades, la Lógica, la Metafísica, la Geometría, la Física, la Ética, la Economía Civil y el Derecho de Gentes y Público. Usted se asusta de ver los propuestos como necesarios, pero yo no trato de formar bachilleres, trato de formar sabios jurisconsultos. Aún hay otro estudio que debe preceder al del Derecho Nacional, y es la Historia de la Nación.

¿Quién podrá entender las leyes de un pueblo sin conocer antes la historia de su gobierno, sus usos y costumbres y, finalmente, de estas mismas leyes?

Este es el más importante de todos los estudios. En vano se tomarán de memoria todas nuestras leyes. Sin estos previos conocimientos es imposible entenderlas. «El saber de las leyes», decía el rey Sabio, «no es tan solamente en aprender a decorar las letras de ellas, más su verdadero entendimiento». 
No basta que las leyes sean buenas, si no son convenientes ellas y la Constitución, usos y costumbres del pueblo para que se han hecho. ¿Quién podrá descubrir esta proporción sin conocer los extremos proporcionales?

Reflexione usted por un instante la muchedumbre y variedad de estas leyes, los diversos tiempos en que se promulgaron, los orígenes de que se han tomado, el carácter de cada uno de los códigos que las contienen. ¿Cómo será posible descubrir su espíritu sin la antorcha de la Historia?

Por ventura, la Constitución, los usos y costumbres de la nación que vivía bajo el gobierno de [los] wisigodos, ¿eran los mismos que en el tiempo del conde don Sancho, cuando se hicieron los primeros fueros de Castilla?, ¿que en el siglo XIII, en que se formaron las Leyes Alfonsinas y se publicó el Fuero Real?, ¿que en los reinados sucesivos en que se promulgaron todas las leyes contenidas en la Recopilación de Castilla? ¿Quién, pues, podrá entender estas leyes sin conocer las épocas en que fueron formadas?

No nos engañemos: esta es una verdad amarga, pero infalible, a que solo retardamos el asentimiento [asentir] por el necio respeto que profesamos a la antigüedad; peor, no hay remedio, es preciso conocerla, respetarla y ceder a la necesidad que ella misma convence.

Pero crean otros lo que quieran y reconozcamos usted y yo, de buena fe, esta necesidad. No seremos los primeros en España. Los buenos estudios han abierto los ojos de un gran número de personas y descubierto las verdaderas causas de nuestro atraso en el conocimiento de las leyes políticas. ¿Por qué se tomará con indolencia el remedio de un mal tan pernicioso?

Sí, amigo mío, sí. La ignorancia es el principio general de los males públi$\cos$. Es preciso declararle la guerra. Es preciso combatir a sangre y fuego este enemigo hasta echarle de nuestros confines y que se vaya a vivir a alguno de los pocos países donde reina todavía.

Si la ciencia del jurisconsulto no tuviese más objeto que la justicia privada, pudiera acaso mirarse, como menos necesaria para ella, el conocimiento de la Historia; pero los objetos de esta ciencia son muchos y muy extendidos, y la mayor parte de ellos está unida a la Constitución.

En España se puede decir que todo el gobierno interior está a cargo de los magistrados; estos deben saber cuál es la verdadera autoridad del príncipe, cuál la de los cuerpos políticos que le representan, cuáles los derechos y cuáles las obligaciones de sus pueblos. $\mathrm{Y}$ ¿habrá quien crea que estos grandes objetos no tienen relación con la Historia? 


\section{Segunda carta}

Confieso a usted, amiguito mío, que es harto difícil empresa al que le propuse en mi carta antecedente. Son pocos, me dice usted, los que no estén convencidos o de la absoluta necesidad o, al menos, de la grande utilidad que hay de averiguar la antigua Constitución, leyes, usos y costumbres de Castilla. Pero ¿dónde se hallan estas noticias?

También confieso que es harto difícil responder a la pregunta, pero usted quiere de buena fe hacer estos estudios y es preciso ayudarle.

Decía Cicerón de la Historia que era la maestra de la vida y, a la verdad, lo será para quien lea y medite cuidadosamente.

En ella puede estudiarse el hombre a sí mismo, estudiando a sus semejantes. El origen de los imperios, las causas de su elevación, su decadencia y su ruina. El vario influjo de las buenas y malas leyes sobre la buena o mala suerte de los Estados y de los hombres. El primero, siempre reservado a la virtud, aun en medio de la persecución; el castigo, nunca retardado al vicio, aun en medio de la prosperidad. Los males que acompañan o siguen a la ignorancia y a la superstición; los bienes derivados de la ilustración y la ciencia. En fin, todos los conocimientos útiles, todas las buenas máximas, todos los saludables documentos que puede necesitar el hombre para el arreglo de su conducta pública y privada están contenidos en la Historia.

(Interrumpida.)

\section{[Esquema sobre la Constitución y leyes de España]}

(c. 1785)

Constitución

De la constitución en particular.

Del origen de la constitución española.

De las épocas.

Godos hasta la restauración.

Reyes de Asturias, de León y condes de Castilla.

Unión de las dos Coronas.

Reunión de la de Castilla y Aragón.

Constitución en particular

Soberano: su autoridad, sus funciones, rentas, patrimonio, regalías.

De la nobleza: oficiales de la Corona, grandes, títulos, hidalgos, obligaciones, derechos, servicios. 
Del clero: las clases, representación civil, funciones, derechos relativos al orden civil.

Del pueblo: sus clases, su dependencia respecto del soberano, de los señores particulares, sus servicios, su representación en el orden civil.

Legislación

De las leyes de España en general y sus orígenes.

De las leyes visigodas.

De los fueros de León y Castilla.

De los fueros municipales y ordenamientos.

Del fuero real.

De las Partidas.

De la Recopilación.

\section{Bibliografía}

ALONSO ROMERO, María Paz; GARRIGA ACOSTA, Carlos (2013). El régimen jurídico de la abogacía en Castilla (siglos XIII-XVIII). Madrid: Universidad Carlos III.

ÁLVAREZ ALONSO, Clara (2000). Un Rey, una Ley, una Religión (Goticismo y Constitución histórica en el debate constitucional gaditano). Historia Constitucional, 1, 1-62.

ÁLVAREZ DE MORALES, Antonio (1993). Estudios de historia de la Universidad española. Madrid: Pegaso.

FERNÁNDEZ SARASOLA, Ignacio (2011). El pensamiento político de Jovellanos. Seis estudios. Oviedo: In Itinere.

GARCÍA MARÍN, José María (2016). El «Fuero Juzgo»: historia y lengua. Madrid: Iberoamericana.

JOVELLANOS, Gaspar Melchor de (1963). Obras publicadas e inéditas. Madrid: Atlas.

JOVELLANOS, Gaspar Melchor de (1986). Obras completas. Gijón: Instituto Feijoo de Estudios del Siglo XVIII, vol. III: Correspondencia, 2. ${ }^{\circ}$

JOVELLANOS, Gaspar Melchor de (1999). Obras completas. Gijón: Instituto Feijoo de Estudios del Siglo XVIII, vol. VII: Diario 2. ${ }^{\circ}$

JOVELLANOS, Gaspar Melchor de (2008). Obras completas. Gijón: Instituto Feijoo de Estudios del Siglo XVIII, vol. X: Escritos económicos.

JOVELLANOS, Gaspar Melchor de (2006). Obras completas. Gijón: Instituto Feijoo de Estudios del Siglo XVIII, vol. XI: Escritos políticos.

JOVELLANOS, Gaspar Melchor de (2010a). Obras completas. Gijón: Instituto Feijoo de Estudios del Siglo XVIII, vol XIII: Escritos pedagógicos 1. ${ }^{\circ}$ 
JOVELLANOS, Gaspar Melchor de (2010b). Obras completas. Gijón: Instituto Feijoo de Estudios del Siglo XVIII, vol XIII: Escritos pedagógicos 2. ${ }^{\circ}$

MALDONADO Y FERNÁNDEZ DEL TORCO, José (1942-1943). Un fragmento de la más antigua Historia del Derecho Español (parte del texto primitivo de la obra del Dr. Espinosa). Anuario de Historia del Derecho Español, 14, 487-500.

MARÍN Y MENDOZA, Joaquín (1950). Historia del Derecho Natural y de Gentes. Madrid: Instituto de Estudios Políticos.

OLAVIDE, Pablo de (1989). Plan de estudios para la Universidad de Sevilla (1767). Sevilla: Universidad de Sevilla.

PESET, Mariano (1971). La formación de los juristas y su acceso al foro en el tránsito de los siglos XVIII y XIX. Revista General de Legislación y Jurisprudencia, 62, 608-631.

PESET, Mariano (1975). Gregorio Mayans y la reforma universitaria: idea de nuevo método que se puede practicar en la enseñanza de las universidades de España, 1 de abril de 1767. Valencia: Ayuntamiento de Oliva, Valencia.

PESET, Mariano; PESET, José Luis (1975). La Universidad Española (Siglos XVIII y XIX). Despotismo Ilustrado y Revolución Liberal. Madrid: Taurus.

ROBERTSON, William (1857). History of the Reign of Charles the Fifth. London: George Routledge \& Co.

SÁNCHEZ, Galo (1927). Sobre las leyes y los fueros de España por el Dr. Francisco de Espinosa. Extracto de la más antigua historia del derecho español. Barcelona: Imprenta de Ortega.

TRUYOL Y SERRA, Antonio (1982). Historia de la Filosofía del Derecho y del Estado. Madrid: Alianza, vol. 2: Del Renacimiento a Kant. 